\title{
Variation in advanced stage at diagnosis of lung and female breast cancer in an English region 2006-2009
}

\author{
G Lyratzopoulos*,', GA Abel', JM Barbiere', CH Brown², BA Rous² and DC Greenberg ${ }^{2}$ \\ 'Department of Public Health and Primary Care, Cambridge Centre for Health Services Research, University of Cambridge, Forvie Site, Robinson Way, \\ Cambridge CB2 OSR, UK; ${ }^{2}$ Eastern Cancer Registration and Information Centre, Unit C - Magog Court, Shelford Bottom, Hinton Way, Cambridge CB22 \\ $3 A D, U K$
}

\begin{abstract}
BACKGROUND: Understanding variation in stage at diagnosis can inform interventions to improve the timeliness of diagnosis for patients with different cancers and characteristics.

METHODS: We analysed population-based data on 17836 and 13286 East of England residents diagnosed with (female) breast and lung cancer during 2006-2009, with stage information on 16460 (92\%) and 10435 (79\%) patients, respectively. Odds ratios (ORs) of advanced stage at diagnosis adjusted for patient and tumour characteristics were derived using logistic regression.

RESULTS: We present adjusted ORs of diagnosis in stages III/IV compared with diagnosis in stages I/II. For breast cancer, the frequency of advanced stage at diagnosis increased stepwise among old women (ORs: 1.21, 1.46, I.68 and I.78 for women aged 70-74, $75-79,80-84$ and $\geqslant 85$, respectively, compared with those aged $65-69, P<0.001)$. In contrast, for lung cancer advanced stage at diagnosis was less frequent in old patients (ORs: $0.82,0.74,0.73$ and $0.66, P<0.00 \mathrm{I}$ ). Advanced stage at diagnosis was more frequent in more deprived women with breast cancer (OR: 1.23 for most compared with least deprived, $P=0.002$ ), and in men with lung cancer (OR: I. I4, $P=0.01 \mathrm{I})$. The observed patterns were robust to sensitivity analyses approaches for handling missing stage data under different assumptions.

CONCLUSION: Interventions to help improve the timeliness of diagnosis of different cancers should be targeted at specific age groups. British Journal of Cancer (2012) I 06, 1068-1075. doi:I0.1038/bjc.2012.30 www.bjcancer.com
\end{abstract}

Published online I March 2012

(C) 2012 Cancer Research UK

Keywords: stage; diagnosis; advanced; age; multiple; imputation

Increasing the proportion of cancer patients who are diagnosed in early stage could help decrease the number of cancer-related deaths (Abdel-Rahman et al, 2009). Therefore, national cancer control policies in several countries currently encompass initiatives supporting early detection and diagnosis (Olesen et al, 2009; Richards, 2009; Coleman et al, 2011).

The evidence base supporting these initiatives, however, is complex and heterogeneous (Richards, 2009). Markers and measures of the timeliness of diagnosis currently in use include short-term survival (NCIN (National Cancer Intelligence Network), 2008a; Møller et al, 2009; Rachet et al, 2009), diagnosis after an emergency hospital admission (NCIN (National Cancer Intelligence Network), 2010), and length of time intervals between symptom onset and diagnosis (Neal and Allgar, 2005; Macleod et al, 2009; Olesen et al, 2009). Stage at diagnosis is an excellent measure of early detection, but UK population-based data regarding this measure are limited. A recent National Audit Office report indicated that the completeness of stage information across English cancer registries is $<40 \%$ (NAO (National Audit Office), 2010).

A better understanding of socio-demographic variation in stage at diagnosis could help stratify and tailor symptom awareness and

*Correspondence: Dr G Lyratzopoulos; E-mail: gl290@medschl.cam.ac.uk Received I November 2011; revised 23 January 2012; accepted 24 January 2012; published online I March 2012 early diagnosis interventions aimed at specific patient groups. We distinguish between 'stratification' that is, the targeting of an intervention to patient populations at a higher risk and 'tailoring', that is, the adaptation (or customising), a generic intervention to make its application more suitable for specific patient groups. An example of this concept relates to targeted interventions to increase breast cancer symptom awareness amongst older women (Forbes et al, 2011). It can also help focus early diagnosis audit efforts (RCGP (Royal College of General Practitioners), 2011) towards the cancers and patient groups with greatest potential for improvement.

Against this background, we have set out to examine sociodemographic variation in stage at diagnosis for female breast and lung cancers (two common cancers responsible for about $30 \%$ of all cancer diagnoses and cancer deaths in England (NCIN (National Cancer Intelligence Network), 2008b) during a recent period.

\section{MATERIALS AND METHODS}

\section{Data}

We analysed information on the stage at diagnosis of East of England patients diagnosed with female breast ('breast' hereafter) and lung cancer during the 4-year period 2006-2009 (International Classification of Diseases (ICD)-10 codes C50 
and $\mathrm{C} 34$, respectively). The study period was chosen as the most recent for which data were available at the time of analysis. Anonymous data were extracted from the Eastern Cancer Registration and Information Centre (ECRIC), a population-based cancer registry covering a general population of $\sim 5.7$ million. The Registry has excellent performance as indicated by conventional measures of cancer registration quality such as death-certificate only registrations $(\sim 0 \%)$ and, uniquely at present among other English cancer registries, it holds information on stage at diagnosis for a particularly high proportion of patients (NAO (National Audit Office), 2010). Stage at diagnosis was classified using the 5th edition of the TNM classification, comprising stages I-IV (Sobin and Wittekind, 1997). Stage at diagnosis was assigned by CHB and $\mathrm{BR}$, integrating clinical, imaging and pathological information. Patient socioeconomic status was ascribed using the income domain of the Index of Multiple Deprivation (IMD) 2004 deprivation score of the Lower Super Output Area (LSOA) of patients' residence in order to define quintile groups $(1=$ least deprived, or 'most affluent'; $5=$ most deprived) (Office of the Deputy Prime Minister, 2004). The income domain of IMD 2004 incorporates information on the proportion of residents of a small area who live in households receiving state-funded support (for example, in the form of income support, unemployment benefit and tax credits). Tumour histological type was categorised into seven groups for breast (infiltrating ductal carcinoma, lobular carcinoma, mixed ductal lobular, other adenocarcinoma, other specified carcinoma, specified not carcinoma tumours and other unspecified) and eight for lung cancer (adenocarcinoma, squamous cell carcinoma, other non-small cell, small cell carcinoma, large cell carcinoma, carcinoid, other specified and other unspecified), using appropriate ICD-Oncology morphology codes (WHO (Word Health Organisation), 2000).

\section{Analysis}

We aimed to examine socio-demographic variation in advanced stage at diagnosis.

Initial analysis was confined to patients with known stage (complete case analysis). Binary logistic regression was used, defining advanced stage at diagnosis both as diagnosis in stages III/IV, or alternatively as diagnosis in stages II-IV (that is, diagnosis other than in stage I). For brevity, we present findings regarding variation in diagnosis in stages III/IV ( $v s$ I-II) in the main paper and append analysis relating to diagnosis at stage I ( $v s$ II-IV). We considered, but did not use, ordinal logistic regression because initial analysis provided evidence of violation of the proportional odds assumption.

Mixed-effects logistic regression models were used to predict advanced stage at diagnosis, adjusting for age group, deprivation quintile and tumour type (both cancers), sex (lung cancer) and screening detection status (breast cancer) as fixed effect categorical variables and including a random effect for Primary Care Trust. Although the UK government plans to abolish Primary Care Trusts in the future, they were responsible for planning, purchasing and quality assuring preventive services and primary or specialist health care for their residents during the study period (20062009). A model using only fixed effect variables for patient characteristics would assume that all observations are independent. In reality, patients within the same organisation may be more similar. Therefore, the models used recognise the hierarchical nature of the data, with patient-level observations being nested within Primary Care Trusts. Therefore, they provided information about patient-level variation (for example, between patients of different age, sex or deprivation status) without the risk of identifying spurious associations arising from potential clustering of different patient subgroups in Primary Care Trusts with higher or lower rates of advanced stage at diagnosis. To explore a potential interaction between age and sex for lung cancer, we have included in a subsequent model an interaction variable for age category (continuous) by sex.

Significance testing was principally based on joint log likelihood ratio tests. We specifically focused aspects of the analysis on patients aged $>70$ years of age because in recent decades improvements in cancer survival in this age group were smaller compared with those observed in younger patients, a finding thought to partially reflect relatively more advanced stage at diagnosis amongst older patients (Quaglia et al, 2009). Therefore, in addition to testing the overall effect of age, we also examined the significance of differences between patients $\geqslant 70$ years compared with patients in all other age groups. Further, tests for linear trend were used to examine the significance of deprivation group gradients by treating deprivation quintile as continuous rather than a categorical variable.

Sensitivity analysis Complete case analysis may be biased, depending on the mechanism responsible for missing data, that is, if data are not 'missing completely at random' (MCAR) (Appendix Table A1). (Sterne et al, 2009). Therefore, in addition, we have used two different sensitivity analysis approaches for handling potential bias arising from missing stage information, bearing in mind different assumptions about the potential mechanisms generating missing data.

First, we used multiple imputation to impute stage. Multiple imputation is a method increasingly used in the context cancer epidemiological studies (He et al, 2008; Nur et al, 2010; Ali et al, 2011). It assumes that data are 'missing at random' (MAR), that is, that any systematic differences between the missing and observed values can be estimated using information from the observed data (note: the MAR assumption does not mean that there are no systematic associations between missing data and specific variables) (Appendix Table $\mathrm{A} 1$ ). We included in imputation models survival, tumour histological grade, basis of diagnosis (that is, whether the diagnosis was verified with histology or not), Primary Care Trust and oestrogen receptor status (breast cancer imputation models only) in addition to all the variables used in the analysis models. All exposure variables used in either the analysis or imputation models were complete, except for grade and oestrogen receptor status (used in imputation models).

Second, as it is not possible to verify the MAR assumption empirically, we conducted sensitivity analysis with a more extreme imputation of missing stage that falls under the assumption of data 'missing not at random' (MNAR) (Appendix Table A1). To do this, we assigned all patients with unknown stage to the advanced stage category (III/IV), and repeated the analysis. This extreme case scenario approach is based on observations that the survival of patients with missing stage information is typically similar to that of patients diagnosed in advanced stage (ECRIC (Eastern Cancer Registration and Information Centre), 2011). We do not expect this extreme case scenario to represent a true situation, but we use it to illustrate how sensitive the complete case and multiple imputation analyses may be to the MCAR or MAR assumptions, respectively. All analysis was conducted in STATA 11 (StataCorp. 2009, College Station, TX, USA), including using the ice and mim commands used for multiple imputation (Royston, 2007). Further details are provided in Appendix Table A1.

\section{RESULTS}

Data relate to 17836 and 13286 patients with incident diagnosis of breast and lung cancer. Information on stage at diagnosis was complete for 16460 (92\%) and 10435 (79\%) patients. The completeness of stage information varied substantially between patients with different socio-demographic characteristics and tumour types - missing stage was more frequent in older patients in particular $(P<0.001$ for both cancers, Appendix Table A2). Among staged patients with breast and lung cancer, $41 \%$ and $15 \%$ 
were diagnosed in stage $\mathrm{I}$, and $86 \%$ and $21 \%$ in stages $\mathrm{I} / \mathrm{II}$, respectively (Table 1 ).

\section{Multivariate complete case analysis}

Breast cancer There was very strong evidence of an association between age and diagnosis in stages III/IV, (Table 2). Specifically for women aged $\geqslant 70$ years, the frequency of diagnosis in stages III/IV increased progressively with older age (odds ratios (ORs): $1.21,1.46,1.68$ and 1.78 for women aged $70-74,75-79,80-84$ and $\geqslant 85$ years, respectively, $P<0.001)$. Increasing deprivation was associated with a greater frequency of stage III/IV diagnosis (joint $\log$ likelihood ratio $P=0.010, \mathrm{p}$ for trend $=0.002$; Table 2 ).

Lung cancer There was very strong evidence of an association between age and advanced stage at diagnosis (Table 3). The frequency of stage III/IV diagnosis decreased progressively among patients aged $\geqslant 70$ years (ORs: of $0.82,0.74,0.73$ and 0.66 for patients aged $70-74,75-79,80-84$ and $\geqslant 85$ years, respectively, $P<0.001)$. There was no evidence for deprivation group differences in lung cancer diagnosis at stages III/IV, in spite of an apparent trend towards lower frequency with increasing deprivation ( $p$ for trend $=0.236$ ) (Table 3 ). There was strong evidence of a higher frequency of advanced stage at diagnosis in men (odds ratio of 1.14 for diagnosis in stages III/IV, $P=0.011$ ). There was no

Table I Proportion of patients by stage, gender, age and deprivation group categories for breast and lung cancer (2006-2009)

\begin{tabular}{|c|c|c|c|c|c|c|}
\hline & \multicolumn{3}{|c|}{ Breast } & \multicolumn{3}{|c|}{ Lung } \\
\hline & $N$ & $\begin{array}{c}\% \text { among } \\
\text { all } \\
\text { patients }\end{array}$ & $\begin{array}{c}\% \text { among } \\
\text { patients } \\
\text { with } \\
\text { known } \\
\text { stage }\end{array}$ & $N$ & $\begin{array}{l}\% \text { among } \\
\text { all patients }\end{array}$ & $\begin{array}{c}\% \text { among } \\
\text { patients } \\
\text { with } \\
\text { known } \\
\text { stage }\end{array}$ \\
\hline \multicolumn{7}{|l|}{ Stage } \\
\hline Stage I & 6788 & $38 \%$ & $41 \%$ & 1534 & $12 \%$ & $15 \%$ \\
\hline Stage II & 7361 & $41 \%$ & $45 \%$ & 670 & $5 \%$ & $6 \%$ \\
\hline Stage III & 1490 & $8 \%$ & $9 \%$ & 3483 & $26 \%$ & $33 \%$ \\
\hline Stage IV & 821 & $5 \%$ & $5 \%$ & 4748 & $36 \%$ & $46 \%$ \\
\hline Unknown & 1376 & $8 \%$ & $\mathrm{n} / \mathrm{a}$ & 2851 & $21 \%$ & $\mathrm{n} / \mathrm{a}$ \\
\hline \multicolumn{7}{|l|}{ Sex } \\
\hline Men & n/a & & & 7684 & $58 \%$ & \\
\hline Women & 17836 & $100 \%$ & & 5602 & $42 \%$ & \\
\hline \multicolumn{7}{|l|}{ Age group ${ }^{\mathrm{a}}$} \\
\hline $15-39$ & 770 & $4 \%$ & & & & \\
\hline $40-44$ & 1091 & $6 \%$ & & n/a & & \\
\hline $45-49$ & 1539 & $9 \%$ & & & & \\
\hline $15-49$ & $\mathrm{n} / \mathrm{a}$ & & & 380 & $3 \%$ & \\
\hline $50-54$ & 2048 & $11 \%$ & & 443 & $3 \%$ & \\
\hline $55-59$ & 1911 & $11 \%$ & & 903 & $7 \%$ & \\
\hline $60-64$ & 2461 & $14 \%$ & & 1525 & $11 \%$ & \\
\hline $65-69$ & 2152 & $12 \%$ & & 1762 & $13 \%$ & \\
\hline $70-74$ & $|49|$ & $8 \%$ & & 2166 & $16 \%$ & \\
\hline $75-79$ & 1590 & $9 \%$ & & 2384 & $18 \%$ & \\
\hline $80-84$ & $132 \mid$ & $7 \%$ & & 2099 & $16 \%$ & \\
\hline$\geqslant 85$ & 1462 & $8 \%$ & & 1624 & $12 \%$ & \\
\hline \multicolumn{7}{|c|}{ Deprivation group } \\
\hline Affluent & 4778 & $27 \%$ & & $247 \mid$ & $19 \%$ & \\
\hline 2 & 4658 & $26 \%$ & & 3072 & $23 \%$ & \\
\hline 3 & 4323 & $24 \%$ & & 3444 & $26 \%$ & \\
\hline 4 & 3081 & $17 \%$ & & 3072 & $23 \%$ & \\
\hline Deprived & 996 & $6 \%$ & & 1227 & $9 \%$ & \\
\hline
\end{tabular}

${ }^{a}$ Younger age groups were categorised differently for the two examined cancers because compared with breast cancer there were fewer patients with lung cancer in the younger age groups. evidence for a differential effect of age in men and women (OR for men $v s$ women per increase in age group category $=0.96,95 \% \mathrm{CI}$ $0.92-1.01, P=0.100)$. Although this may reflect lack of power, the size of the interaction indicates that a large synergistic effect is unlikely.

Examining variation in diagnosis in stage I $v s$ II-IV produced overall similar findings for lung cancer. For breast cancer, the findings were similar in respect of variation in older age, but there was no evidence of deprivation differences (Appendix Tables A3 and A4).

Sensitivity analysis Repeating the analysis using multiple imputation of missing stage information produced highly similar values and patterns to those derived by the complete case analysis (Tables 4 and 5). Specifically, for both breast and lung cancer the same patterns of variation by age, deprivation and sex (for lung cancer only) were apparent. Repeating the analysis using the extreme case scenario approach (missing stage $=$ advanced stage) produced similar patterns of variation for lung cancer. For breast cancer, in the extreme case scenario that the true stage at diagnosis of all women with missing information was either stage III or IV, deprivation differences in advanced stage at diagnosis would be smaller. The full output from all analysis models is provided in Appendix Table A5.

\section{DISCUSSION}

\section{Summary of findings and comparisons with other literature}

Using population-based data, we identified substantial sociodemographic variation in the stage at diagnosis of breast and lung cancer. Breast cancer patients who were $\geqslant 70$ years of age had a higher frequency of advanced stage at diagnosis. Conversely, age $\geqslant 70$ was associated with a lower frequency of advanced stage at diagnosis for lung cancer. Advanced stage at diagnosis was more frequent in more deprived patients with breast cancer. Men with lung cancer had a higher frequency of advanced stage at diagnosis.

Table 2 Breast cancer. Independent associations of age and deprivation with advanced stage at diagnosis (i.e., stage III/IV vs stage I/II) ${ }^{a}(n=16460)$

\begin{tabular}{lcccc}
\hline & \multicolumn{5}{c}{$\begin{array}{c}\text { Lower } \\
\mathbf{9 5 \%} \\
\text { Odds } \\
\text { ratio }\end{array}$} & $\begin{array}{c}\text { Higher } \\
\text { confidence } \\
\text { interval }\end{array}$ & $\begin{array}{c}\mathbf{9 5 \%} \\
\text { confidence } \\
\text { interval }\end{array}$ & P \\
\hline $15-39$ & 1.15 & 0.89 & 1.48 & \\
$40-44$ & 1.02 & 0.81 & 1.28 & \\
$45-49$ & 0.91 & 0.74 & 1.14 & \\
$50-54$ & 0.92 & 0.74 & 1.14 & \\
$55-59$ & 0.90 & 0.72 & 1.12 & \\
$60-64$ & 0.91 & 0.74 & 1.12 & \\
$65-69$ & Reference & & & \\
$70-74$ & 1.21 & 0.98 & 1.49 & \\
$75-79$ & 1.46 & 1.20 & 1.78 & \\
$80-84$ & 1.68 & 1.37 & 2.07 & \\
$\geqslant 85$ & 1.78 & 1.45 & 2.18 & \\
Most affluent & Reference & & & \\
2 & 1.16 & 1.02 & 1.32 & \\
3 & 1.12 & 0.98 & 1.28 & \\
4 & 1.29 & 1.12 & 1.49 & \\
Deprived & 1.23 & 1.00 & 1.52 & \\
\hline
\end{tabular}

aFrom logistic regression models, with stage III/IV vs stage I/II diagnosis as the binary outcome variable. Models were adjusted for age, deprivation, tumour type and diagnosis through screening or symptomatically, and included a random effect for

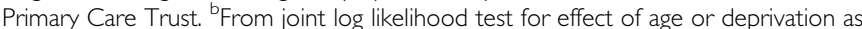
applicable. ${ }^{C}$ From joint log likelihood ratio tests for significance of difference between patients aged $\geqslant 70$ years and patients in all other age groups. ${ }^{\mathrm{d}}$ From models with deprivation quintile group entered as a continuous variable. 
Table 3 Lung cancer. Independent associations of age, deprivation and sex with advanced stage diagnosis (i.e., stage III/IV vs stage I/II) ${ }^{a}(n=10435)$

\begin{tabular}{lcccc} 
& $\begin{array}{c}\text { Odds } \\
\text { ratio }\end{array}$ & $\begin{array}{c}\text { Lower 95\% } \\
\text { confidence } \\
\text { interval }\end{array}$ & $\begin{array}{c}\text { Higher 95\% } \\
\text { confidence } \\
\text { interval }\end{array}$ & $\boldsymbol{P}$ \\
\hline Women & $\begin{array}{c}\text { Reference } \\
1.14\end{array}$ & 1.03 & 1.25 & $0.011^{\mathrm{b}}$ \\
Men & 1.33 & 0.93 & 1.90 & $<0.00 \mathrm{I}^{\mathrm{b}}(<0.00 \mathrm{I})^{\mathrm{c}}$ \\
$15-49$ & 1.00 & 0.74 & 1.35 & \\
$50-54$ & 1.26 & 0.99 & 1.61 & \\
$55-59$ & 0.96 & 0.79 & 1.18 & \\
$60-64$ & Reference & & & \\
$65-69$ & 0.82 & 0.68 & 0.97 & \\
$70-74$ & 0.74 & 0.62 & 0.88 & \\
$75-79$ & 0.73 & 0.61 & 0.88 & \\
$80-84$ & 0.66 & 0.54 & 0.81 & \\
$\geqslant 85$ & 0.94 & 0.81 & 1.09 & \\
Most affluent & Reference & & & \\
2 & 0.97 & 0.83 & 1.12 & \\
3 & 0.98 & 0.84 & 1.14 & \\
4 & 0.81 & 0.66 & 0.99 & \\
Deprived & $0.236)^{\mathrm{d}}$ \\
\hline
\end{tabular}

${ }^{\text {a}}$ From logistic regression models, with stage II-IV vs stage I or stage III/IV vs stage I/II diagnosis as the binary outcome variable. Models were adjusted for age, sex, deprivation and tumour type, and included a random effect for Primary Care Trust. bFrom joint log likelihood test for effect of sex, age or deprivation as applicable. 'From joint log likelihood ratio tests for significance of difference between patients aged

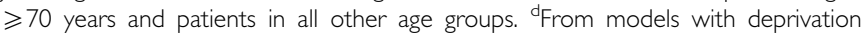
quintile group entered as a continuous variable.

Table 4 Breast cancer. Summary of outputs obtained by complete case analysis and sensitivity analyses (odds ratios for stage III/IV vs I/II).

\begin{tabular}{lccc}
\hline & $\begin{array}{c}\text { Complete } \\
\text { case }^{\text {analysis }}{ }^{\mathbf{a}}\end{array}$ & $\begin{array}{c}\text { Multiple } \\
\text { imputation }\end{array}$ & $\begin{array}{c}\text { Missing } \\
\text { stage }=\mathbf{I I - I V}\end{array}$ \\
\hline $15-39$ & 1.15 & 1.13 & 1.08 \\
$40-44$ & 1.02 & 1.01 & 0.85 \\
$45-49$ & 0.91 & 0.91 & 0.85 \\
$50-54$ & 0.92 & 0.90 & 0.93 \\
$55-59$ & 0.90 & 0.88 & 0.81 \\
$60-64$ & 0.91 & 0.90 & 0.86 \\
$65-69$ & Reference & & \\
$70-74$ & 1.21 & 1.23 & 1.08 \\
$75-79$ & 1.46 & 1.49 & 1.30 \\
$80-84$ & 1.68 & 1.74 & 1.77 \\
$\geqslant 85$ & 1.78 & 1.84 & 2.21 \\
Most affluent & Reference & & \\
2 & 1.16 & 1.20 & 1.12 \\
3 & 1.12 & 1.16 & 1.07 \\
4 & 1.29 & 1.32 & 1.21 \\
Deprived & 1.23 & 1.27 & 1.07 \\
\hline
\end{tabular}

${ }^{a}$ This column replicates information included in Table 2 - presented here for ease of comparisons.

The findings were robust to multiple imputation of missing stage (under the MAR assumption). Similar patterns of variation were also observed for extreme case scenario analysis (under the MNAR assumption of missing stage $=$ advanced stage), except that deprivation differences in advanced stage diagnosis for breast cancer were smaller.

Regarding age differences in stage at diagnosis, no apparent age patterns were apparent in a recent analysis of the US breast cancer data (CDC, 2010). For lung cancer, evidence from Denmark indicates a lower frequency of advanced stage at diagnosis with increasing age, as observed in our own study (Dalton et al, 2011).

For breast cancer, the observed socioeconomic differences concord with other evidence from the United Kingdom, United States and Canada, indicating a higher frequency of advanced stage
Table 5 Lung cancer. Summary of outputs obtained by complete case analysis and sensitivity analyses (odds ratios for stage III/IV vs I/II)

\begin{tabular}{|c|c|c|c|}
\hline & $\begin{array}{l}\text { Complete } \\
\text { case analysis }^{a}\end{array}$ & $\begin{array}{l}\text { Multiple } \\
\text { imputation }\end{array}$ & $\begin{array}{c}\text { Missing } \\
\text { stage }=\text { stage } \\
\text { II-IV }\end{array}$ \\
\hline Women & Reference & & \\
\hline Men & 1.14 & 1.13 & 1.15 \\
\hline $15-49$ & 1.33 & 1.23 & 1.31 \\
\hline $50-54$ & 1.00 & 0.96 & 0.95 \\
\hline $55-59$ & 1.26 & 1.22 & 1.23 \\
\hline $60-64$ & 0.96 & 0.95 & 0.95 \\
\hline $65-69$ & Reference & & \\
\hline $70-74$ & 0.82 & 0.80 & 0.82 \\
\hline $75-79$ & 0.74 & 0.72 & 0.75 \\
\hline $80-84$ & 0.73 & 0.73 & 0.78 \\
\hline$\geqslant 85$ & 0.66 & 0.68 & 0.76 \\
\hline Most affluent & Reference & & \\
\hline 2 & 0.94 & 0.97 & 0.95 \\
\hline 3 & 0.97 & 1.01 & 0.97 \\
\hline 4 & 0.98 & 1.04 & 0.99 \\
\hline Deprived & 0.81 & 0.91 & 0.82 \\
\hline
\end{tabular}

This column replicates information included in Table 3 - presented here for ease of comparisons.

at diagnosis among women of lower socioeconomic position. (Adams et al, 2004; Clegg et al, 2009; Cuthbertson et al, 2009; Booth et al, 2010). For lung cancer, studies from Canada, Denmark and Sweden have indicated only limited socioeconomic differences in advanced stage at diagnosis (Berglund et al, 2010; Booth et al, 2010; Dalton et al, 2011). A previous UK study reported lower frequency of advanced stage at diagnosis in more deprived patients (Brewster et al, 2001). The findings of our study are similar with previous UK research, although there was no independent evidence of an association $(P$ for trend $=0.236)$ that may reflect the lack of power.

\section{Strengths and limitations}

The principal strengths of the study are its population-based design, and the high quality and completeness of information on stage at diagnosis and other tumour variables. Unlike previous studies in this field, we adjusted the analysis for tumour subtype and employed sensitivity analyses approaches using different assumptions about potential mechanisms responsible for missing stage data. Previous studies on stage at diagnosis of breast cancer did not encompass adjustment for screening or symptomatic detection status, and this factor complicated the interpretation of age and socioeconomic differences in stage at diagnosis (Macleod et al, 2000; Adams et al, 2004; Cuthbertson et al, 2009). In contrast, our findings indicate that substantial age and deprivation differences in stage at diagnosis of breast cancer exist independently of whether a woman was diagnosed by screening or after symptomatic presentation. A previous UK study on stage at diagnosis of lung cancer only reported on socioeconomic differences (not encompassing age and sex differences) in the mid-1990s (Brewster et al, 2001). Therefore, we believe the findings enrich substantially the currently available evidence on patterns of stage at diagnosis in patients with breast and lung cancer.

The study also has certain limitations. We could not adjust the analysis for ethnicity - a potential confounder of deprivation in particular. During the study period, the proportion of East of England residents belonging to ethnic minorities was relatively small, particularly among persons $\geqslant 65$ years (where the majority of cancer cases occur); $\sim 97 \%$ of the East of England resident population in this age group were estimated as being British White in 2007 (ONS (Office for National Statistics), 2009). Given the demographic characteristics of the East of England population, the 
findings can be considered to chiefly describe socio-demographic variation in stage at diagnosis among White British patients. Nevertheless, examination of patterns of stage at diagnosis by ethnic group is warranted in the future.

We examined data from a single region that includes about $10 \%$ of the total English population. Socioeconomic differences in short-term cancer survival, however, (a marker of early diagnosis) are relatively similar across different English regions (Rachet et al, 2009). Inequalities in cancer treatment patterns observed in East of England cancer patients are also similar to those observed nationwide (Wishart et al, 2010). These considerations indicate that the observed socio-demographic patterns of stage at diagnosis can be applicable to the rest of the English population. The size of the East of England population ( $\sim 5.7$ million) is similar to that of several European countries.

In common with previous authoritative UK research (Brewster et al, 2001; Adams et al, 2004; Rachet et al, 2010), we used an areabased measure of socioeconomic status in our study, relating to the population characteristics of highly homogeneous small areas (LSOA) (Woods et al, 2005). Socioeconomic status can be measured either directly (for example, by measuring a person's income, occupation or education) or indirectly (ecologically) by measuring the characteristics of the population of a small area (Liberatos et al, 1988). Both direct and area-based measures of socioeconomic status have limitations (Sloggett et al, 2007), and might be affected by lack of homogeneity within groups (for example, between patients of the same social class, income, education or neighbourhood) (Carstairs and Morris, 1989). Using an area-based measure of socioeconomic status may have either underestimated or overestimated socioeconomic gradients in stage at diagnosis compared with direct measures (Sloggett et al, 2007), and research examining such gradients using both area-based and direct measures would be useful.

\section{Interpretation and research policy implications}

A key consideration in interpreting the findings is whether the observed variation in advanced stage at diagnosis, particularly in relation to age, can be considered avoidable. In theory, the findings might in part reflect differences in the malignant potential of tumours between patients of different ages. The analysis was, however, adjusted for tumour subtype. This makes it less likely that age differences in tumour biology can be responsible for major part of the observed age differences in stage at diagnosis.

For breast cancer, it is possible that the observed variation in stage at diagnosis reflects differences in the awareness of cancer symptoms between different patient groups. Awareness of cancer symptoms and signs in the United Kingdom is socio-demographically patterned, and is lower among individuals aged $>65$ and of lower socioeconomic status (Robb et al, 2009). The findings of the study would support the targeting of breast cancer awareness interventions at older women (Forbes et al, 2011).

The lower frequency of advanced stage at diagnosis among older lung cancer patients could reflect more frequent use of chest $X$ ray investigations in older patients (for example, in the context of investigating either a chest infection or other clinical presentations such as shortness of breath). A recent population study from Denmark indicated a lower frequency of advanced stage lung cancer diagnosis among patients with higher levels of comorbidity and also (as observed in our study) with increasing age (Dalton et al, 2011). Another potential explanation is that 'stage for stage' lung cancer is more symptomatic in older patients, for example, either because of a higher propensity to present with concomitant chest infection (prompting earlier investigation and leading to earlier diagnosis) or earlier presentation of dyspnoea because of physiologically declining lung capacity in older age. Further research in this area is clearly needed to explore the validity of these hypotheses, and to identify the mechanisms responsible for excess risk of advanced stage at diagnosis in relatively younger patients.

There was a substantial excess risk of advanced stage at diagnosis among breast cancer women $\geqslant 70$ years of age. These differences should not be dismissed as clinically unimportant; in our study sample, one-third of women with breast cancer were aged $\geqslant 70$ years. In the United Kingdom, life expectancy for women aged 70 and 80 year-old is 16.5 and 9.5 years, respectively (ONS (Office for National Statistics), 2011). Decreasing the frequency of advanced stage at diagnosis among women $\geqslant 70$ years can therefore contribute substantially to reducing avoidable mortality in this age group. In contrast, the findings also identify opportunities for achieving earlier stage diagnosis of lung cancer in relatively young patients (for example, those aged $60-74$ years).

\section{CONCLUSION}

There is substantial potential for improvements in early diagnosis in older patients with breast cancer and in relatively younger patients with lung cancer. The findings could help guide breast and lung cancer early diagnosis initiatives and research focused on individuals of different age groups at highest risk of advanced stage at diagnosis. These could, for example, encompass age stratified and tailored cancer symptoms awareness interventions, or educational interventions for physicians and healthcare professionals, targeted at patients of different age groups. We provide an exemplar of how population-based cancer registration information could help support national initiatives aimed at improving early diagnosis, and inform further policy and research.

\section{ACKNOWLEDGEMENTS}

We thank all staffs of the Eastern Cancer Registration and Information Centre and Dr David Gilligan for his insightful comments regarding older age advanced stage diagnosis patterns for lung cancer. GL is funded by a Post-Doctoral Research Fellowship award from the National Institute for Health Research.

\section{REFERENCES}

Abdel-Rahman M, Stockton D, Rachet B, Hakulinen T, Coleman MP (2009) What if cancer survival in Britain were the same as in Europe: how many deaths are avoidable? $B r$ J Cancer 101(Suppl 2): S115-S124

Adams J, White M, Forman D (2004) Are there socioeconomic gradients in stage and grade of breast cancer at diagnosis? Cross sectional analysis of UK cancer registry data. BMJ 329(7458): 142

Ali AM, Dawson SJ, Blows FM, Provenzano E, Ellis IO, Baglietto L, Huntsman D, Caldas C, Pharoah PD (2011) Comparison of methods for handling missing data on immunohistochemical markers in survival analysis of breast cancer. Br J Cancer 104(4): 693-699

Berglund A, Holmberg L, Tishelman C, Wagenius G, Eaker S, Lambe M (2010) Social inequalities in non-small cell lung cancer management and survival: a population-based study in central Sweden. Thorax 65(4): $327-333$

Booth CM, Li G, Zhang-Salomons J, Mackillop WJ (2010) The impact of socioeconomic status on stage of cancer at diagnosis and survival: a population-based study in Ontario, Canada. Cancer 116(17): $4160-4167$ 
Brewster DH, Thomson CS, Hole DJ, Black RJ, Stroner PL, Gillis CR (2001) Relation between socioeconomic status and tumour stage in patients with breast, colorectal, ovarian, and lung cancer: results from four national, population based studies. BMJ 322: $830-831$

Carstairs V, Morris R (1989) Deprivation and mortality: an alternative to social class? Community Med 11(3): 210-219

CDC (Centres for Disease Control) (2010) Morbidity and Mortality Weekly Report. Surveillance of Screening-Detected Cancers (Colon and Rectum, Breast, and Cervix) - United States, 2004-2006. http://www.cdc.gov/ mmwr/pdf/ss/ss.5909.pdf. Last accessed 23 January 2012

Clegg LX, Reichman ME, Miller BA, Hankey BF, Singh GK, Lin YD, Goodman MT, Lynch CF, Schwartz SM, Chen VW, Bernstein L, Gomez SL, Graff JJ, Lin CC, Johnson NJ, Edwards BK (2009) Impact of socioeconomic status on cancer incidence and stage at diagnosis: selected findings from the surveillance, epidemiology, and end results: National Longitudinal Mortality Study. Cancer Causes Control 20(4): $417-435$

Coleman MP, Forman D, Bryant H, Butler J, Rachet B, Maringe C, Nur U, Tracey E, Coory M, Hatcher J, McGahan CE, Turner D, Marrett L, Gjerstorff ML, Johannesen TB, Adolfsson J, Lambe M, Lawrence G, Meechan D, Morris EJ, Middleton R, Steward J, Richards MA, ICBP Module 1 Working Group (2011) Cancer survival in Australia, Canada, Denmark, Norway, Sweden, and the UK, 1995-2007 (the International Cancer Benchmarking Partnership): an analysis of population-based cancer registry data. Lancet 377(9760): 127-138

Cuthbertson SA, Goyder EC, Poole J (2009) Inequalities in breast cancer stage at diagnosis in the trent region, and implications for the NHS Breast Screening Programme. J Public Health (Oxf) 31(3): $398-405$

Dalton SO, Frederiksen BL, Jacobsen E, Steding-Jessen M, Osterlind K, Schüz J, Osler M, Johansen C (2011) Socioeconomic position, stage of lung cancer and time between referral and diagnosis in Denmark, 2001-2008. Br J Cancer 105(7): $1042-1048$

ECRIC (Eastern Cancer Registration and Information Centre) (2011) Stage distribution of cancers diagnosed in 2009 in the East of England by cancer site and area of residence. http://www.ecric.nhs.uk/docs/ ECRIC incidenceXstage_2009.pdf. Last accessed 23 January 2012

Forbes LJ, Linsell L, Atkins L, Burgess C, Tucker L, Omar L, Ramirez AJ (2011) A promoting early presentation intervention increases breast cancer awareness in older women after 2 years: a randomised controlled trial. Br J Cancer 105(1): $18-21$

He Y, Yucel R, Zaslavsky AM (2008) Misreporting, missing data, and multiple imputation: improving accuracy of Cancer Registry Databases. Chance (N Y) 21(3): 55-58

Liberatos P, Link BG, Kelsey JL (1988) The measurement of social class in epidemiology. Epidemiol Rev 10: 87-121

Macleod U, Mitchell ED, Burgess C, Macdonald S, Ramirez AJ (2009) Risk factors for delayed presentation and referral of symptomatic cancer: evidence for common cancers. Br J Cancer 101(Suppl 2): S92-S101

Macleod U, Ross S, Gillis C, McConnachie A, Twelves C, Watt GC (2000) Socio-economic deprivation and stage of disease at presentation in women with breast cancer. Ann Oncol 11(1): 105-107

Møller H, Linklater KM, Robinson D (2009) A visual summary of the EUROCARE-4 results: a UK perspective. Br J Cancer 101(Suppl 2): S110-S114

NAO (National Audit Office) (2010) Department of Health. Delivering the Cancer Reform Strategy. Report by the Comptroller and Auditor General. HC 568. Session 2010-2011. http://www.nao.org.uk/publications/1011/ cancer_reform_strategy.aspx. Last accessed 23 January 2012

NCIN (National Cancer Intelligence Network) (2008a) One Year Cancer Survival Trends, England, 1985-2004; One Year Cancer Survival By Cancer Network, England, 2000-2004. http://www.ncin.org.uk/ publications/reports/default.aspx. Last accessed 23 January 2012

NCIN (National Cancer Intelligence Network) (2008b) Cancer Incidence and Mortality By Cancer Network, UK, 2005. http://www.ncin.org.uk/ publications/reports/default.aspx. Last accessed 23 January 2012

NCIN (National Cancer Intelligence Network) (2010) Routes to Diagnosis NCIN Data Briefing. http://www.ncin.org.uk/publications/data_briefings/ routes_to_diagnosis.aspx. Last accessed 23 January 2012
Neal RD, Allgar VL (2005) Sociodemographic factors and delays in the diagnosis of six cancers: analysis of data from the 'National Survey of NHS Patients: Cancer'. Br J Cancer 92(11): 1971 - 1975

Nur U, Shack LG, Rachet B, Carpenter JR, Coleman MP (2010) Modelling relative survival in the presence of incomplete data: a tutorial. Int J Epidemiol 39(1): 118-128

Office of the Deputy Prime Minister (2004) The English Indices of Deprivation 2004: Summary (revised). http://www.communities.gov.uk/ documents/communities/pdf/131206.pdf. Last accessed 23 January 2012

Olesen F, Hansen RP, Vedsted P (2009) Delay in diagnosis: the experience in Denmark. Br J Cancer 101(Suppl 2): S5-S8

ONS (Office for National Statistics) (2009) Population Estimates by Ethnic Group (experimental), Mid-2009. http://www.ons.gov.uk/ons/ publications/re-reference-tables.html?edition $=\mathrm{tcm} \% 3 \mathrm{~A} 77-50029$. Last accessed 23 January 2012

ONS (Office for National Statistics) (2011) England and Wales, Interim Life Tables, $1980-82$ to 2008-10. http://www.ons.gov.uk/ons/publications/ re-reference-tables.html?edition $=\mathrm{tcm} \% 3 \mathrm{~A} 77-22332$. Last accessed 23 January 2012

Quaglia A, Tavilla A, Shack L, Brenner H, Janssen-Heijnen M, Allemani C, Colonna M, Grande E, Grosclaude P, Vercelli M (2009) The cancer survival gap between elderly and middle-aged patients in Europe is widening. Eur J Cancer 45(6): $1006-1016$

Rachet B, Ellis L, Maringe C, Chu T, Nur U, Quaresma M, Shah A, Walters S, Woods L, Forman D, Coleman MP (2010) Socioeconomic inequalities in cancer survival in England after the NHS cancer plan. Br J Cancer 103(4): $446-453$

Rachet B, Maringe C, Nur U, Quaresma M, Shah A, Woods LM, Ellis L, Walters S, Forman D, Steward J, Coleman MP (2009) Population-based cancer survival trends in England and Wales up to 2007: an assessment of the NHS cancer plan for England. Lancet Oncol 10(4): 351-369

RCGP (Royal College of General Practitioners) (2011) National Audit of Cancer Diagnosis in Primary Care. http://www.rcgp.org.uk/pdf/National_ Audit_of_Cancer_Diagnosis_in_Primary-Care.pdf. Last accessed 23 January 2012

Richards MA (2009) The national awareness and early diagnosis initiative in England: assembling the evidence. Br J Cancer 101(Suppl 2): S1-S4

Robb K, Stubbings S, Ramirez A, Macleod U, Austoker J, Waller J, Hiom S, Wardle J (2009) Public awareness of cancer in Britain: a populationbased survey of adults. Br J Cancer 101(Suppl 2): S18-S23

Royston P (2007) Multiple imputation of missing values: further update of ice, with an emphasis on interval censoring. Stata J. 7: 445-464

Sloggett A, Young H, Grundy E (2007) The association of cancer survival with four socioeconomic indicators: a longitudinal study of the older population of England and Wales 1981-2000. BMC Cancer 7: 20

Sobin LH, Wittekind CH (eds), International Union Against Cancer (UICC) (1997) TNM Classification of Malignant Tumors. 5th edition John Wiley \& Sons Inc: New York

Sterne JA, White IR, Carlin JB, Spratt M, Royston P, Kenward MG, Wood AM, Carpenter JR (2009) Multiple imputation for missing data in epidemiological and clinical research: potential and pitfalls. BMJ 338: b2393

WHO (Word Health Organisation) (2000) International Classification of Diseases for Oncology, 3rd Edition (ICD-O-3). http://www.who.int/ classifications/icd/adaptations/oncology/en/. Last accessed 23 January 2012

Wishart GC, Greenberg DC, Chou P, Brown CH, Duffy S, Purushotham AD (2010) Treatment and survival in breast cancer in the Eastern Region of England. Ann Oncol 21(2): 291-296

Woods LM, Rachet B, Coleman MP (2005) Choice of geographic unit influences socioeconomic inequalities in breast cancer survival. Br J Cancer 92: 1279-1282

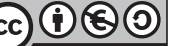

This work is licensed under the Creative Commons Attribution-NonCommercial-Share Alike 3.0 Unported License. To view a copy of this license, visit http://creativecommons.org/licenses/by-nc-sa/3.0/ 


\section{APPENDIX}

Table Al Additional details on methods of sensitivity analysis and imputation. Potential mechanisms responsible for missing stage data

Assumed mechanism
'Missing completely at random' (MCAR):
there are no systematic differences
between the missing values and the
observed values.

'Missing at random' (MAR): any systematic difference between the missing and observed values can be explained by differences in observed data. Under this assumption, although patients with missing stage information may have a higher probability of being diagnosed in advanced stage compared with patients with observed stage, this probability can be estimated from the associations of stage with age, sex tumour type and so on among patients with observed stage.

'Missing not at random' (MNAR): even after information from patients with observed stage and its associations with other variables are taken into account, systematic differences remain between patients with missing and observed stage. For example, because more advanced stage at diagnosis is more likely to remain unobserved.

How each assumption relates to the analysis in this paper

'Complete case analysis' will give unbiased (although less precise) estimates under the MCAR assumption. Said differently, complete case analysis implicitly assumes that data are 'missing completely at random'. Although this assumption does not hold (we know that stage is more likely to be missing in older patients), the potential for bias is minimised by the high level of stage data completeness.

The assumption that stage data are 'missing at random' underpins sensitivity analysis using multiple imputation. This assumption becomes more reasonable by also including in imputation models variables other than those used in the analysis models (e.g., survival, grade and basis of diagnosis). ${ }^{a}$

The assumption that stage data are 'missing not at random' underpins sensitivity analysis using substitution of unknown stage values with advanced stage. We do not expect this extreme case scenario to be true, but it illustrate how sensitive the complete case and multiple imputation analyses may be to the MCAR or the MAR assumptions, respectively.

aWen only outcome data are missing (e.g., on patient stage), complete case analysis will give unbiased estimates under the assumption that data are 'missing at random' when the missing outcome is dependent only on variables included in the analysis model. This assumption is more reasonable than the 'missing completely at random' one, but may still not hold; however, it can become even more reasonable by including additional variables in the imputation models, as applied in this study.

\section{Further details on imputation}

We used the STATA ice command for multiple imputation (see reference by Royston et al (2007) of main paper). For (female) breast cancer, imputation models included information on age, deprivation, tumour type, screening detection status, tumour grade, oestrogen receptor status, histological verification status, Primary Care Trust and survival. For lung cancer, imputation models included information on age, sex, deprivation, tumour type, tumour grade, histological verification status and Primary Care Trust and survival.

Stage was treated as a binary variable (stage III/IV vs I/II). Grade was treated as an ordinal variable with four levels for colorectal and lung cancer, and three levels for breast cancer. All other variables except for survival were treated as categorical. For survival we used the Nelson-Aalen estimate of the cumulative hazard function along with an indicator variable describing vital status at end of follow-up.

Informed by considerations of the proportion of missing data for different variables, 50 imputed data sets were generated for either cancer. All imputed data sets were each analysed separately and then combined using Rubin's rules, using the STATA mim command.
Analysis models on the imputed data sets included the same variables as those used in the analysis models using the complete case analysis approach, that is, age, deprivation, tumour type and screening detection status for breast cancer, and age, sex, deprivation and tumour type for lung cancer, including a random effect for Primary Care Trust.

Table A2 Predictors of missing stage

\begin{tabular}{|c|c|c|c|c|}
\hline & Total & Staged & $\%$ staged & $p\left(\chi^{2}\right)$ \\
\hline \multicolumn{5}{|l|}{ (a) Breast cancer } \\
\hline Affluent & 4778 & 4385 & 92 & $0.490^{a}$ \\
\hline 2 & 4658 & 4321 & 93 & \\
\hline 3 & 4323 & 4007 & 93 & \\
\hline 4 & 3081 & 2809 & 91 & \\
\hline Deprived & 996 & 938 & 94 & \\
\hline $15-39$ & 770 & 709 & 92 & $<0.001^{b}$ \\
\hline $40-44$ & $109 \mid$ & 1036 & 95 & \\
\hline $45-49$ & 1539 & 1437 & 93 & \\
\hline $50-54$ & 2048 & 1930 & 94 & \\
\hline $55-59$ & 1911 & 1832 & 96 & \\
\hline $60-64$ & 2461 & 2350 & 95 & \\
\hline $65-69$ & 2152 & 2036 & 95 & \\
\hline $70-74$ & |49| & 1393 & 93 & \\
\hline $75-79$ & 1590 & 1458 & 92 & \\
\hline $80-84$ & $|32|$ & 1133 & 86 & $<0.001^{\mathrm{c}}$ \\
\hline$\geqslant 85$ & 1462 & $1 \mid 46$ & 78 & \\
\hline Infiltrating ductal carcinoma & 12826 & 12030 & 94 & $<0.001^{b}$ \\
\hline Lobular carcinoma & 2099 & 1922 & 92 & \\
\hline Mixed ductal lobular & $121 \mid$ & 1164 & 96 & \\
\hline Other adenocarcinoma & 709 & 653 & 92 & \\
\hline Other specified carcinoma & 89 & 79 & 89 & \\
\hline Other unspecified & 863 & 609 & 71 & \\
\hline Specified not carcinoma & 39 & 3 & 8 & \\
\hline All patients & 17836 & 16460 & 92 & \\
\hline \multicolumn{5}{|l|}{ (b) Lung cancer } \\
\hline Men & 5602 & 4392 & 78 & $0.736^{a}$ \\
\hline Women & 7684 & 6043 & 79 & \\
\hline Affluent & $247 \mid$ & 1900 & 77 & $0.009^{b}$ \\
\hline 2 & 3072 & 2402 & 78 & \\
\hline 3 & 3444 & 2734 & 79 & \\
\hline 4 & 3072 & 2397 & 78 & \\
\hline Deprived & 1227 & 1002 & 82 & \\
\hline $15-49$ & 380 & 287 & 76 & $<0.001^{\mathrm{a}}$ \\
\hline $50-54$ & 443 & 359 & 81 & \\
\hline $55-59$ & 903 & 743 & 82 & \\
\hline $60-64$ & 1525 & 1248 & 82 & \\
\hline $65-69$ & 1762 & 1416 & 80 & \\
\hline $70-74$ & 2166 & 1759 & 81 & \\
\hline $75-79$ & 2384 & 1899 & 80 & \\
\hline $80-84$ & 2099 & 1597 & 76 & $<0.001^{c}$ \\
\hline$\geqslant 85$ & 1624 & 1127 & 69 & \\
\hline Adenocarcinoma & 2366 & 1901 & 80 & $<0.001^{\mathrm{a}}$ \\
\hline Carcinoid & 100 & 16 & 16 & \\
\hline Large cell carcinoma & 145 & 128 & 88 & \\
\hline Other non-small cell & 2475 & 2117 & 86 & \\
\hline Small cell carcinoma & 1464 & 1150 & 79 & \\
\hline Specified other & 10 & 2 & 20 & \\
\hline Squamous cell carcinoma & 2351 & 2040 & 87 & \\
\hline Unspecified other & 4375 & 3081 & 70 & \\
\hline All patients & 13286 & 10435 & 79 & \\
\hline
\end{tabular}

(a) ${ }^{\text {a }}$ rom univariate logistic regression for stage completeness, with deprivation quintile group entered as a continuous exposure variable. ${ }^{b}$ From $\chi^{2}$-test. 'From log likelihood ratio tests for significance of difference between the 'older' age groups (i.e. age groups $\geqslant 70$ years) and other age groups. (b) ${ }^{a}$ From $\chi^{2}$-test. ${ }^{b}$ From univariate logistic regression for stage completeness, with deprivation quintile group entered as a continuous variable. 'From log likelihood ratio tests for significance of difference between the 'older' age groups (i.e., age groups $\geqslant 70$ years) and other age groups. 
Table A3 Findings in relation to variation in breast cancer diagnosis at stage I vs stages II-IV

\begin{tabular}{|c|c|c|c|c|}
\hline & \multicolumn{4}{|c|}{ Stage II-IV vs stage I } \\
\hline & $\begin{array}{l}\text { Odds } \\
\text { ratio }\end{array}$ & $\begin{array}{l}\text { Lower } 95 \% \\
\text { confidence } \\
\text { interval }\end{array}$ & $\begin{array}{l}\text { Higher } 95 \% \\
\text { confidence } \\
\text { interval }\end{array}$ & $P$ \\
\hline \multicolumn{5}{|l|}{ Breast cancer } \\
\hline $15-39$ & 2.04 & 1.69 & 2.47 & $<0.001^{a}$ \\
\hline $40-44$ & 1.67 & 1.42 & 1.96 & \\
\hline $45-49$ & 1.57 & 1.35 & 1.81 & \\
\hline $50-54$ & 1.30 & 1.14 & 1.48 & \\
\hline $55-59$ & 1.23 & 1.08 & 1.41 & \\
\hline $60-64$ & 1.06 & 0.93 & 1.20 & \\
\hline $65-69$ & Reference & & & \\
\hline $70-74$ & 1.45 & 1.25 & 1.67 & $\left(<0.00 \mathrm{I}^{\mathrm{b}}\right)$ \\
\hline $75-79$ & 1.70 & 1.47 & 1.97 & \\
\hline $80-84$ & 1.99 & 1.69 & 2.34 & \\
\hline$\geqslant 85$ & 2.41 & 2.04 & 2.86 & \\
\hline Most affluent & Reference & & & $0.335^{\mathrm{a}}$ \\
\hline 2 & 1.03 & 0.94 & 1.13 & $\left(0.172^{\circ}\right)$ \\
\hline 3 & 1.03 & 0.94 & 1.13 & \\
\hline 4 & 1.11 & 1.00 & 1.24 & \\
\hline Deprived & 1.00 & 0.86 & 1.17 & \\
\hline
\end{tabular}

Independent associations of age and deprivation with diagnosis in stage I vs $\|-\mathrm{IV}^{\mathrm{d}}$ ( $n=16460){ }^{\text {a }}$ From joint log likelihood test for effect of age or deprivation as applicable. 'From joint log likelihood ratio tests for significance of difference between patients aged $\geqslant 70$ years and patients in all other age groups. "From models with deprivation quintile group entered as a continuous variable. ${ }^{\mathrm{d}}$ From logistic regression models, with diagnosis in stage II $-I V$ vs stage I as the binary outcome variable. Models were adjusted for age, deprivation, tumour type and diagnosis through screening or symptomatic presentation, and included a random effect for Primary Care Trust.

Table A4 Findings in relation to variation in lung cancer diagnosis at stage I vs stages II-IV

\begin{tabular}{|c|c|c|c|c|c|c|c|c|c|c|}
\hline & \multicolumn{3}{|c|}{$\begin{array}{c}\text { Complete case } \\
\text { analysis }\end{array}$} & \multicolumn{4}{|c|}{$\begin{array}{l}\text { Multiple } \\
\text { imputation }\end{array}$} & \multicolumn{3}{|c|}{$\begin{array}{l}\text { Missing stage }= \\
\text { stage III/IV }\end{array}$} \\
\hline & OR & $\begin{array}{l}95 \% \\
\text { LCI }\end{array}$ & $\begin{array}{l}95 \% \\
\text { UCI }\end{array}$ & OR & $\begin{array}{l}95 \% \\
\mathrm{LCl}\end{array}$ & $\begin{array}{l}95 \% \\
\text { UCl }\end{array}$ & FMI & OR & $\begin{array}{l}95 \% \\
\text { LCI }\end{array}$ & $\begin{array}{l}95 \% \\
\text { UCI }\end{array}$ \\
\hline Women & Ref. & - & - & Ref. & - & - & - & Ref. & - & - \\
\hline & 1.1 & 1.03 & 1.25 & 1.13 & 1.03 & 1.25 & 0.170 & 1.15 & 1.05 & 1.27 \\
\hline $15-49$ & 1.33 & 0.93 & 1.90 & 1.23 & 0.86 & 1.75 & 0.197 & 1.31 & & - \\
\hline 50-54 & 1.00 & 0.74 & 1.35 & 0.96 & 0.71 & 1.30 & 0.157 & 0.95 & 0.93 & 1.84 \\
\hline $55-59$ & 1.26 & 0.99 & 1.61 & 1.22 & 0.96 & 1.55 & 0.119 & 1.23 & 0.71 & 1.27 \\
\hline 60-64 & 0.96 & 0.79 & 1.18 & 0.95 & 0.78 & 1.16 & 0.150 & 0.95 & 0.97 & 1.56 \\
\hline 65-69 & Ref. & - & - & Ref. & - & - & - & - & 0.78 & 1.15 \\
\hline 70-7 & 0.82 & 0.68 & 0.97 & 0.80 & 0.68 & 0.96 & 0.109 & 0.82 & 0.69 & 0.98 \\
\hline 75-79 & 0.74 & 0.62 & 0.88 & 0.72 & 0.60 & 0.86 & 0.171 & 0.75 & 0.64 & 0.89 \\
\hline 80-84 & 3 & 0.61 & 0.88 & 0.73 & 0.61 & 0.87 & 0.16 & 0.78 & 0.65 & 0.93 \\
\hline & 0.66 & 0.54 & 0.81 & 0.68 & 0.55 & 0.83 & 0.23 & 0.76 & 0.62 & 0.92 \\
\hline Most affluent & Ref. & - & - & Ref. & - & - & - & Ref. & - & - \\
\hline & 0.94 & 0.81 & 1.09 & 0.97 & 0.84 & 1.12 & 0.138 & 0.95 & 0.82 & 1.10 \\
\hline & 0.97 & 0.83 & & 1.01 & 0.87 & 1.17 & 0.184 & 0.97 & 0.84 & 1.12 \\
\hline & & 0.84 & 1.14 & 1.04 & 0.89 & 1.21 & 0.209 & 0.99 & 0.86 & 1.15 \\
\hline Depr & 0.81 & 0.66 & 0.99 & 0.91 & 0.75 & 1.10 & 0.186 & 0.82 & 0.67 & 0.99 \\
\hline len & Ref. & & & Ref. & & & & Ref. & & \\
\hline & 0.91 & 0.79 & 1.05 & 0.89 & 0.77 & 1.02 & 0.116 & 0.83 & 0.72 & 0.95 \\
\hline Othe & 2.07 & & & 1.97 & 1.70 & 2.29 & & & 1.61 & 2.18 \\
\hline & 4.06 & 3.23 & 5.12 & 3.90 & 3.10 & 4.92 & 0.207 & 3.94 & 3.14 & 4.94 \\
\hline & 1.51 & 0.97 & 2.36 & 1.44 & 0.93 & 2.22 & 0.065 & 1.2 & 0.83 & 1.99 \\
\hline & 0.02 & 0.00 & & 0.02 & 0.00 & 0.15 & 0.764 & 1.53 & 0.87 & 2.70 \\
\hline & 0.41 & 0.03 & 6.63 & 0.74 & 0.06 & 9.27 & 0.627 & 2.30 & 0.29 & 18.35 \\
\hline Unspe & 1.94 & 1.67 & 2.24 & 1.85 & 1.59 & 2.15 & 0.289 & 2.07 & 1.80 & 2.37 \\
\hline
\end{tabular}

Abbreviations: $\mathrm{OR}=$ odds ratio; $\mathrm{Ref}=$ reference; $\mathrm{LCl}=$ lower confidence interval; $\mathrm{UCl}=$ upper confidence interval; $\mathrm{FMI}=$ fraction of missing information (for each respective variable category, it denotes the proportion of the estimation that used imputed missing information).
G Lyratzopoulos et al

Table A5 Full outputs of all analysis models presented in main paper (for stage III/IV vs I/II comparisons)

\begin{tabular}{|c|c|c|c|c|c|c|c|c|}
\hline \multicolumn{3}{|c|}{$\begin{array}{l}\text { Complete case } \\
\text { analysis }\end{array}$} & \multicolumn{3}{|c|}{$\begin{array}{l}\text { Multiple } \\
\text { imputation }\end{array}$} & \multicolumn{3}{|c|}{$\begin{array}{l}\text { Missing stage }= \\
\text { stage III/IV }\end{array}$} \\
\hline & $95 \%$ & $95 \%$ & & $95 \% \quad 95 \%$ & & & & $95 \%$ \\
\hline OR & LCI & UCI & OR & LCI UCI & FMI & OR & LCI & UCI \\
\hline
\end{tabular}

\begin{tabular}{|c|c|c|c|c|c|c|c|c|c|c|}
\hline \multicolumn{11}{|c|}{ (a) Breast cancer, stage III/IV vs stage I-II } \\
\hline $15-39$ & 1.15 & 0.89 & 1.48 & 1.13 & 0.88 & 1.46 & 0.062 & 1.08 & 0.87 & 1.34 \\
\hline $40-44$ & 1.02 & 0.81 & 1.28 & 1.01 & 0.80 & 1.27 & 0.069 & 0.85 & 0.70 & 1.05 \\
\hline $45-49$ & 0.91 & 0.74 & 1.14 & 0.91 & 0.73 & 1.13 & 0.088 & 0.85 & 0.70 & 1.02 \\
\hline $50-54$ & 0.92 & 0.74 & 1.14 & 0.90 & 0.72 & 1.11 & 0.066 & 0.93 & 0.78 & 1.11 \\
\hline $55-59$ & 0.90 & 0.72 & 1.12 & 0.88 & 0.71 & 1.09 & 0.058 & 0.81 & 0.67 & 0.98 \\
\hline $60-64$ & 0.91 & 0.74 & 1.12 & 0.89 & 0.73 & 1.10 & 0.076 & 0.86 & 0.72 & 1.02 \\
\hline $65-69$ & Ref. & & & Ref. & & & & Ref. & & \\
\hline $70-74$ & 1.21 & 0.98 & 1.49 & 1.22 & 0.99 & 1.50 & 0.064 & 1.08 & 0.90 & 1.29 \\
\hline $75-79$ & 1.46 & 1.20 & 1.78 & 1.50 & 1.23 & 1.82 & 0.062 & 1.30 & 1.09 & 1.54 \\
\hline $80-84$ & 1.68 & 1.37 & 2.07 & 1.75 & 1.43 & 2.15 & 0.115 & 1.77 & 1.49 & 2.10 \\
\hline$\geqslant 85$ & 1.78 & 1.45 & 2.18 & 1.86 & 1.52 & 2.27 & 0.128 & 2.21 & 1.87 & 2.62 \\
\hline Most affluent & Ref. & & & Ref. & & & & Ref. & & \\
\hline 2 & 1.16 & 1.02 & 1.32 & 1.20 & 1.05 & 1.36 & 0.107 & 1.12 & 1.00 & 1.25 \\
\hline 3 & 1.12 & 0.98 & 1.28 & 1.16 & 1.02 & 1.32 & 0.091 & 1.07 & 0.95 & 1.19 \\
\hline 4 & 1.29 & 1.12 & 1.49 & 1.32 & 1.15 & 1.52 & 0.116 & 1.21 & 1.07 & 1.36 \\
\hline Deprived & 1.23 & 1.00 & 1.52 & 1.27 & 1.03 & 1.57 & 0.149 & 1.07 & 0.89 & 1.29 \\
\hline Infiltrating ductal carcinoma & Ref. & & & Ref. & & & & Ref. & & \\
\hline Lobul & 1.59 & 1.39 & 1.81 & 1.62 & 1.42 & 1.84 & 0.061 & 1.54 & 1.38 & 1.73 \\
\hline Mixe & 1.09 & 0.90 & I. & 1.10 & 0.91 & 1.33 & 0.051 & 0.97 & 0.82 & 1.15 \\
\hline Othe & 0.99 & 0.79 & 1.25 & 0.98 & 0.78 & 1.23 & 0.058 & 0.99 & 0.82 & 1.20 \\
\hline Oth & 0.58 & 0.26 & 1.26 & 0.58 & 0.27 & 1.27 & 0.118 & 0.90 & 0.52 & 1.54 \\
\hline Other & 3.90 & 3.26 & 4.66 & 4.01 & 3.37 & 4.77 & 0.254 & 4.57 & 3.93 & 5.32 \\
\hline Specified not carcinoma & 3.57 & 0.28 & 46.04 & 1.78 & 0.14 & 22.25 & 0.870 & 81.48 & 19.36 & 342.93 \\
\hline $\begin{array}{l}\text { Screening detection } \\
\text { status- no }\end{array}$ & Ref. & & & & & & & & & \\
\hline $\begin{array}{l}\text { Screening detection } \\
\text { status-yes }\end{array}$ & 0.26 & 0.22 & 0.31 & 0.27 & 0.22 & 0.32 & 0.030 & 0.20 & 0.17 & 0.24 \\
\hline \multicolumn{11}{|c|}{ (b) Lung cancer, odds ratios of stage IIIIIV vs stage I/II } \\
\hline Women & Ref. & & & Ref. & & & & Ref. & & \\
\hline Men & 1.14 & 1.03 & 1.25 & 1.13 & 1.03 & 1.25 & 0.170 & 1.15 & 1.05 & 1.27 \\
\hline & 1.33 & 0.93 & 1.90 & 1.23 & 0.86 & 1.75 & 0.197 & 1.31 & & \\
\hline & 1.00 & 0.74 & 1.35 & 0.96 & 0.71 & 1.30 & 0.157 & 0.95 & 0.93 & 1.84 \\
\hline & 1.26 & 0.99 & 1.61 & 1.22 & 0.96 & 1.55 & 0.119 & 1.23 & 0.71 & 1.27 \\
\hline & 0.96 & 0.79 & 1.18 & 0.95 & 0.78 & 1.16 & 0.150 & 0.95 & 0.97 & 1.56 \\
\hline & Ref. & & & Ref. & & & & & 0.78 & 1.15 \\
\hline & 0.82 & 0.68 & 0.97 & 0.80 & 0.68 & 0.96 & 0.109 & 0.82 & 0.69 & 0.98 \\
\hline & 0.74 & 0.62 & 0.88 & 0.72 & 0.60 & 0.86 & 0.171 & 0.75 & 0.64 & 0.89 \\
\hline $80-84$ & 0.73 & 0.61 & 0.88 & 0.73 & 0.61 & 0.87 & 0.16 & 0.78 & 0.65 & 0.93 \\
\hline$\geqslant 85$ & 0.66 & 0.54 & 0.81 & 0.68 & 0.55 & 0.83 & 0.23 & 0.76 & 0.62 & 0.92 \\
\hline Most affluent & Ref. & & & Ref. & & & & Ref. & & \\
\hline 2 & 0.94 & 0.81 & 1.09 & 0.97 & 0.84 & 1.12 & 0.138 & 0.95 & 0.82 & 1.10 \\
\hline 3 & 0.97 & 0.83 & 1.12 & 1.01 & 0.87 & 1.17 & 0.184 & 0.97 & 0.84 & 1.12 \\
\hline 4 & 0.98 & 0.84 & 1.14 & 1.04 & 0.89 & 1.21 & 0.209 & 0.99 & 0.86 & 1.15 \\
\hline Deprived & 0.81 & 0.66 & 0.99 & 0.91 & 0.75 & 1.10 & 0.186 & 0.82 & 0.67 & 0.99 \\
\hline Aden & Ref. & & & Ref. & & & & Ref. & & \\
\hline Squan & 0.91 & 0.79 & 1.05 & 0.89 & 0.77 & 1.02 & 0.116 & 0.83 & 0.72 & 0.95 \\
\hline Other & 2.07 & 1.77 & 2.42 & 1.97 & 1.70 & 2.29 & 0.099 & 1.87 & 1.61 & 2.18 \\
\hline Small & 4.06 & 3.23 & 5.12 & 3.90 & 3.10 & 4.92 & 0.207 & 3.94 & 3.14 & 4.94 \\
\hline Large & 1.51 & 0.97 & 2.36 & 1.44 & 0.93 & 2.22 & 0.065 & 1.29 & 0.83 & 1.99 \\
\hline Carcinoid $^{\mathrm{a}}$ & 0.02 & 0.00 & 0.18 & 0.02 & 0.00 & 0.15 & 0.764 & 1.53 & 0.87 & 2.70 \\
\hline Specified other ${ }^{\mathrm{a}}$ & 0.41 & 0.03 & 6.63 & 0.74 & 0.06 & 9.27 & 0.627 & 2.30 & 0.29 & 18.35 \\
\hline Unspecified other & 1.94 & 1.67 & 2.24 & 1.85 & 1.59 & 2.15 & 0.289 & 2.07 & 1.80 & 2.37 \\
\hline
\end{tabular}

Abbreviations: $\mathrm{FMI}=$ fraction of missing information (for each respective variable category, it denotes the proportion of the estimation that used imputed missing information); $\mathrm{LCl}=$ lower confidence interval; $\mathrm{OR}=$ odds ratio; Ref = reference; $\mathrm{UCl}=$ upper confidence interval. ${ }^{a}$ For these two groups, large differences are apparent between the analysis under the missing stage = stage IV analysis and either complete case analysis or multiple imputation. Both these groups were small and had a particularly small proportion of patients with observed stage $(<20 \%)$, most of whom were in stage $|/| \mid l$. The above indicate that the missing stage= stage IV assumption for patients with missing stage in these two groups is unlikely to be reasonable; we nevertheless present findings for consistency. 